\title{
1 The Impact Of Long-term Grazing Intensity On Functional 2 Groups Richness, Biomass, And Species Diversity In an Inner 3 Mongolian Steppe Grassland
}

Yousif Mohamed Zainelabdeen ${ }^{12 \#}$, Ahmed Ibrahim Ahmed ${ }^{1}$ \#, Ruirui Yan ${ }^{*}$, Xiaoping Xin $^{1 *}$, Cao Juan ${ }^{1}$, Jimoh Saheed Olaide ${ }^{3}$

${ }^{1}$ Laboratory of Grassland Science, Institute of Agricultural Resources and Regional Planning, Chinese Academy of Agricultural Sciences, Beijing 100081, China

2 Agricultural Research Corporations (ARC), Wad Medani 126, Sudan

${ }^{3}$ Grassland Research Institute, Chinese Academy of Agricultural Sciences, Hohhot 010010, China ${ }^{*}$ Corresponding author at 12 Zhongguancun South Street, Beijing 100081, China. E-mail addresses: yanruirui@caas.cn(R.Yan),xinxiaoping@caas.cn (X.Xin).

\# The first three authors contributed equally to this work and can be considered co-first authors.

\section{Abstract}

Livestock grazing is one of the major land uses, causing changes in the plant community's structure and grasslands composition. We assessed the effect of grazing intensity on aboveground biomass, species richness, and plant functional group (PFG) diversity in a temperature meadow steppe in Hulunbuir in northern China, involving 78 plant species from eight functional groups. Four grazing intensity classes were characterized, including light, moderate, heavy, and no grazing, based on stocking rates of $0.23,0.46,0.92$, and 0.00 animal units per hectare. Our results show that the richness of short species, including perennial short grass, perennial short grass, and legume increased under light to moderate grazing, while no effect of grazing was observed on the richness of shrubs. With increasing grazing intensity, the aboveground biomass of perennial tall grasses and perennial tall forbs decreased significantly, while that of annual/biennial plant functional groups increased. The community diversity and evenness of annual/biennial plants increased significantly with grazing intensity. We concluded that heavy grazing has negative impacts on plant functional group richness and aboveground biomass.

Keywords: Functional group; species richness; biomass; diversity; grazing intensity

\section{Introduction}

Livestock grazing is considered one of the primary biotic factors that affect the natural grassland ecosystem functions (Olff and Ritchie 1998). Specifically, species diversity response to grazing intensity varies from location to location (De Bello, et al. 2006). This suggests that the magnitude of grazing intensity 

has the potential to impact species diversity, which often leads to vegetation degradation (Bakker 1998). Previous studies have shown that the positive impact of grazing intensity in natural grasslands implies that historical traditional grazing does not have a negative impact on these ecosystems (Montalvo, et al. 1993; Verdú, et al. 2007). For example, (Proulx and Mazumder 1998) reported that species richness responds positively to heavy grazing intensity in a highly productive environment. It is noteworthy, however, that grazing intensity is a complex disturbance that can affect the grassland communities, both directly and indirectly (Papanikolaou, et al. 2011), because it has the potential to change the vegetation structure, growth, and composition of different species, while also affecting the abiotic components of the ecosystem (Facelli and Springbett 2009). Whereas changes in grassland species composition and richness are induced by grazing intensity (Bergmeier, et al. 2003; Suding, et al. 2008), the influence of the latter on plant functional groups at the species level could differ (DÍAz, et al. 2007; Díaz, et al. 2001; McIntyre, et al. 1999; NoyMeir, et al. 1989). However, these results were often inconsistent, more research is needed to improve our understanding of how grazing intensities affects species and plant communities (e.g., the species in the same plant functional group can respond differently to grazing intensity due to palatability or species structure), especially in Hulunbuir grasslands (Foggin 2008; Le, et al. 2014).

The disturbance caused by large herbivore grazing on plant functional groups' life is an important factor affecting plant community composition. In some environments, the composition and structure of plant and animal species are influenced by grazing intensities, while in other places, the environmental characteristics of the area, including weather conditions and climate, are sometimes more important. Grazing directly influences plant community composition through the physical removal of plant parts. It can also indirectly influence plant communities by organizing ecosystem productivity or changing nutrient patterns between plants of different sizes. Therefore, grazing can change the quantity, diversity, and distribution of organisms in the ecosystem. Grazing intensities also influence grass species performance and grassland environment (Saccone, et al. 2014)

Biodiversity is a complex concept that allows for a variety of possible definitions. In a broad sense, from species to various forms of life, are defined as ecosystems (Hill 1973; Wilson, et al. 2016). At the community level, the diversity index reflects the distribution of the basic plant species in an environment. However, the term 'diversity index' could also be used to depict other categorizations such as functional groups and genetic types within the ecological environment. The entities of interest are usually individual animals or plants, where individual species, biomass, or coverage can be used as a measure of abundance (Dumont, et al. 2009; Fanselow, et al. 2011) It has been reported that grazing intensities had different impacts on single species' aboveground biomass and biodiversity, which is documented by significant effects of grazing intensity on biomass and species diversity for this study. 
Diversity can be divided into three parts: $\alpha$ diversity, which is the richness of a single site or specific community; $\beta$ diversity, which is the difference of flora between different sites or communities; and $\gamma$ diversity, which is the difference between geographical regions (Sepkoski Jr 1988). $\alpha$ diversity measures the aggregation within the community and reflects the fine division of ecological resources by species, while $\beta$ diversity can be used to measure the degree of species composition turnover in the environmental gradient, potentially reflecting the degree of habitat selection or allotment. Gamma and beta diversities are similar, although gamma is measured at a larger spatial scale; it reflects the locality or degree of locality of a biota. (Whittaker and Rh 1977) retained the term "gamma diversity" for the combination of alpha and beta diversity, which he also called "complete diversity" (Whittaker 1972).

Palatability refers to the characteristic or condition of plant stimulating animal selective response, also defined as a pleasant taste. Preference can be expressed in the relative of time that animals graze different species. Preferences were left to animals to choose from, basically behavioral. Relative preference refers to the proportion choice between two or more species. In addition to palatability, many other factors affect food selection (Heady 1964).

Broadly, the objective of this study was to understand how different grazing intensities influence species richness, diversity and plant functional groups in the Hulunbuir meadow steppe ecosystem. Our goal was to determine the effect of grazing intensity on aboveground biomass and species richness based on species palatability. We hypothesized that perennial tall grasses are more palatable than other functional groups (e.g., shrubs are spiny, and Liliaceae are often poisonous). Plant functional groups are greatly used proportion of variation in traits among species. Therefore, the use of functional groups is essentially a traitbased approach. Plant species in functional groups have similar characteristics and ecological similarity (Thomas, et al. 2019).

Furthermore, we evaluated the response of plant functional groups (PFGs) diversity to grazing intensity. Here, we hypothesize that the diversity of functional groups differs across grazing intensities. To clarify, species diversity implies a measure of both species number and abundance while species richness is just the number of plant species found in an environment.

\section{Materials And Methods}

Study area

The research was conducted in the Hulunbuir meadow steppe in northeast Inner Mongolia of China. 
The mean maximum temperature in Hulunbuir is measured at $36.17{ }^{\circ} \mathrm{C}$ in July, and a minimum temperature of $-48.5{ }^{\circ} \mathrm{C}$ in January. The annual frost-free period ranges from 85 to 155 days. Sunshine duration accounts for 2650-3000 hours per year. The area receives an average annual precipitation of 350 to $400 \mathrm{~mm}, 80 \%$ of which falls between July and September. Chernozem soils are commonly found here. The most dominant grass species in Hulunbuir are Leymus chinensis, Carex duriuscula, Pulsatilla turczaninovii, Stipa baicalensis, Cleistogenes squarrosa, Artemisia tanacefolia and Thalictrum squarrosum.

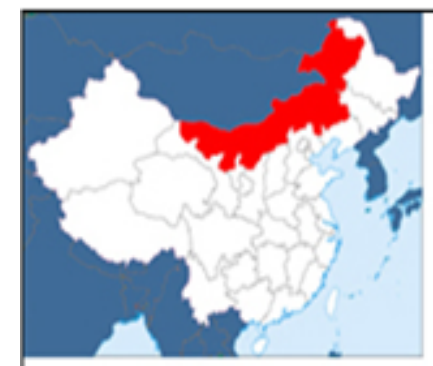

\section{Experimental Layout} respectively.

Fig.1. The geographical location of the Hulunbuir meadow steppe.

The experiment was carried out on 600 hectares of natural grassland, with three grazing intensities and a no-grazing control (NG). The grazing intensities were $0,0.23,0.46$, and 0.92 animal unit (AU) ha ${ }^{-1}$ for $\mathrm{NG}$, light grazing (LG), moderate grazing (MG), and heavy grazing (HG), respectively. A $500 \mathrm{~kg}$ adult cattle is defined as $1 \mathrm{AU}$. The NG plot has been fenced and excluded from grazing since 2014. Each treatment plot occupies 5 ha of grassland with three replicates. In total, 12 plots were randomly distributed. The experiments were conducted during the grazing seasons (June to October) in 2014-2017. Drinking water was provided from an external source for the anmals. The numbers of animals grazed in each of the experimental plot was $0,2,4$ and 8 heads of 250-300 $\mathrm{kg}$ calves for the treatment of NG, LG, MG and HG,

In each treatment plot, five sampling quadrats of $1 \mathrm{~m}^{2}$ were randomly located. Plants in each quadrat were trimmed to $2.5 \mathrm{~cm}$ in height. We divided the harvested species parts trimmed off into eight PFGs: perennial tall grass, perennial short grass, shrubs, legumes, Liliaceae herbs, annual/biennial plants, 
perennial tall forbs, and perennial short forbs (Ma, et al. 2010). Based on our sampling records, we estimated the species richness. To explore potential compositional changes related to grazing intensity, we also estimated the diversity index of each PFG, defined as the ratio of the rate of the abundance of species belonging to a particular functional group to the rate of occurrence of all the species captured in each quadrat. The following formulas were used to calculate alpha diversity (Shannon-Wiener diversity index $(\mathrm{H})$ ), the Beta diversity index ( $\beta$ ), Pielou evenness index (E), and important value (IV).

$1-\mathrm{H}(\alpha)=-\sum(\mathrm{Pi} * \ln \mathrm{Pi}) \quad$ where, $\mathrm{H}=$ the Shannon diversity index, $\mathrm{Pi}=$ Number of individuals of species $\mathrm{i} /$ total number of species

2- $\beta=\gamma-\alpha$, where $\beta=$ beta diversity, $\gamma=$ Gamma diversity, $\alpha=$ alpha diversity

3- $\mathrm{E}=-\sum(\mathrm{Pi} * \ln \mathrm{Pi}) / \mathrm{LnS}(\mathrm{Y}$ an and Lu 2015)

4- $\quad I V=\frac{R C+R D+R B}{3}$

where $\mathrm{RC}$ is the relative coverage of the total species, $\mathrm{RD}$ is the relative density and $\mathrm{RB}$ is the relative biomass. Gamma diversity, also known as site diversity, is the total species richness of a site (Zhang, et al. 2014).

\section{Data analysis}

We used a one-way analysis of variance (ANOVA) to examine the changes in species richness and diversity of each PFGs (all plant species) across the grazing intensity treatments using the SAS 9.2 (SAS, 2007). Duncan's multiple comparison test was used to compute the significant difference among the treatments at $p<0.05$. Similarly, for each replication, the difference in the composition of the dominant species and the 8 PFGs was tested by ANOVA.

\section{Results}

\section{Grazing impact on species richness}

The species richness of the PFGs as influenced by grazing intensity were summarized in Table 1. A significant difference $(p<0.05)$ was observed between the treatments for perennial short grass (PSG), perennial tall forbs (PTF) and Liliaceae herb (LILY). Perennial short grass species were higher in the LG and MG plots (Table 1). With an increase in grazing intensity, species richness of PSG decreased under HG but recorded a significantly similar value with the NG treatment. The species richness of PTFs and LILY was higher at sampling plots subjected to light and moderate grazing, as well as the NG treatment. Further, heavy grazing reduced the richness of these species (Table 1). 
Table 1. Species richness of plant functional groups under four grazing intensities.

159

\begin{tabular}{|c|c|c|c|c|c|}
\hline Functional groups & $\begin{array}{l}\text { Total Species } \\
\text { richness }\end{array}$ & NG & LG & MG & HG \\
\hline PTG & 14 & $3.8 \pm 0.6$ & $3.6 \pm 0.1$ & $3.4 \pm 0.2$ & $2.7 \pm 0.3$ \\
\hline PSG & 17 & $3.6 \pm 0.4 b$ & $4.9 \pm+0.3 \mathrm{a}$ & $5 \pm 0.14 a$ & $3.6 \pm 0.1 b$ \\
\hline PTF & 23 & $8.1 \pm 0.5 \mathrm{a}$ & $1.1 \pm 0.1 \mathrm{a}$ & $8.4 \pm 0.3 \mathrm{a}$ & $5.8 \pm 0.1 \mathrm{~b}$ \\
\hline PSF & 27 & $6.5 \pm 4.4$ & $6.5 \pm+0.3$ & $7.2 \pm+0.1$ & $6.7 \pm 0.4$ \\
\hline LILY & 16 & $4.3 \pm 0.6 \mathrm{a}$ & $4.6 \pm 0.44 \mathrm{a}$ & $3.8 \pm 0.1 \mathrm{a}$ & $3.3 \pm 0.5 b$ \\
\hline LEGU & 10 & $2.5 \pm 0.4$ & $2.8 \pm 0.4$ & $2.3 \pm 0.4$ & $2.1 \pm 0.3$ \\
\hline $\mathrm{ABP}$ & 5 & $0.91 \pm 0.4$ & $1.4 \pm 0.5$ & $1.2 \pm 0.1$ & $1.2 \pm 0.1$ \\
\hline SHR & 8 & $0.9 \pm 0.08$ & $4.4 \pm 1.2$ & $1.3 \pm 0.1$ & $1.1 \pm 0.1$ \\
\hline Total & 120 & & & & \\
\hline
\end{tabular}
grazing, HG: Heavy grazing. PTG= Perennial tall grass, $\mathrm{PSG}=$ Perennial short grass, PTF= Perennial tall forbs, $\mathrm{PSF}=$ Perennial short forbs, LILY= Liliaceae herb, LEGU= legumes, $\mathrm{ABP}=$ annual/biennial plants and $\mathrm{SHR}=$ shrubs. NG plot had the highest PTG $\left(102.0 \mathrm{~g} / \mathrm{m}^{2}\right)$ biomass while the least was recorded for MG $\left(21.0 \mathrm{~g} / \mathrm{m}^{2}\right)$ and HG (4.0 g/ $\left.\mathrm{m}^{2}\right)$ plots. Similarly, PTF (47.4) and LILY herbs (14.7) biomasses were higher in the NG plot 167 and the lowest was recorded in the $\mathrm{HG}\left(10.9\right.$ and $\left.0.98 \mathrm{~g} / \mathrm{m}^{2}\right)$ plot. The ABP functional group strongly 168 increased in the HG intensity plot (2.2) while the NG (0.7) and MG (0.43) intensity plots recorded similar 169 lower values. All the grazing intensity plots had higher SHR biomass than the NG plot. However, there 170 were no significant differences $(p>0.05)$ in perennial short forbs (PSG), PSF, and LEGU biomass across 171 the grazing treatments imposed. 
Table 2. Responses of aboveground biomass $\mathrm{g} / \mathrm{m} 2$ of different plant functional groups to gradients of grazing intensity.

179 Mean values and $( \pm \mathrm{SE})$ for each group of plots for different plant functional groups

\begin{tabular}{llllll}
\hline $\begin{array}{l}\text { Functional } \\
\text { groups }\end{array}$ & Species number & NG & LG & MG & HG \\
\hline PTG & 6 & & & \\
PSG & 7 & $102.0 \pm 12.9 \mathrm{a}$ & $54.6 \pm 6.1 \mathrm{~b}$ & $21.0 \pm 2.9 \mathrm{c}$ & $4.0 \pm 1.1 \mathrm{c}$ \\
PTF & 18 & $26.3 \pm 3.8$ & $33.3 \pm 4.7$ & $36.4 \pm 1.1$ & $24.6 \pm 4.7$ \\
PSF & 16 & $47.4 \pm 3.9 \mathrm{a}$ & $40.8 \pm 2.6 \mathrm{ab}$ & $30.3 \pm 5.2 \mathrm{~b}$ & $10.96 \pm 1.5 \mathrm{c}$ \\
LILY & 8 & $17.9 \pm 4.4$ & $13.5 \pm 1.1$ & $14.6 \pm 2.9$ & $11.2 \pm 0.95$ \\
LEGU & 9 & $14.7 \pm 5.3 \mathrm{a}$ & $11.4 \pm 0.7 \mathrm{ab}$ & $4.0 \pm 0.6 \mathrm{bc}$ & $0.98 \pm+0.1 \mathrm{c}$ \\
ABP & 11 & $3.6 \pm 1.5$ & $3.6 \pm 2.6$ & $3.3 \pm 2.1$ & $1.5 \pm 0.2$ \\
SHR & 3 & $0.7 \pm 0.4 \mathrm{~b}$ & $0.98 \pm 0.4 \mathrm{ab}$ & $0.43 \pm 0.07 \mathrm{~b}$ & $2.2 \pm 0.57 \mathrm{a}$ \\
Total & 78 & $1.2 \pm 0.4 \mathrm{~b}$ & $4.4 \pm 1.2 \mathrm{a}$ & $5.6 \pm 0.09 \mathrm{a}$ & $4.8 \pm 1.3 \mathrm{a}$ \\
\hline
\end{tabular}

a,b,c Means in the same row with different superscript are significantly different. NG: No grazing, LG: Light grazing, MG: Moderate grazing, HG: Heavy grazing. $\mathrm{PTG}=$ Perennial tall grass, $\mathrm{PSG}=$ Perennial short grass, $\mathrm{PTF}=\mathrm{Perennial}$ tall forbs, $\mathrm{PSF}=$ Perennial short forbs, LILY= Liliaceae herb, LEGU= legumes, $\mathrm{ABP}=$ annual/biennial plants and $\mathrm{SHR}=\mathrm{shrubs}$.

With grazing intensity, the decrease of dominance species was higher in PTG and PTF (3.85\%), while the PSG and PSF dominant species increased with grazing intensity 3.85\% and 8.97\% respectively (Table3). Most of the C4 photosynthetic pathway dominant species appeared in PTF (5.13\%) and PSF (2.56\%). About $17.94 \%$ of the total grassland species showed a positive reaction to grazing intensity by increasing their aboveground biomass (Table 3), while $16.66 \%$ showed a negative response to grazing intensity by decreasing their aboveground biomass. 
Table 3. Proportional increase and decrease in the aboveground biomass and species photosynthetic pathway of plant

197 functional groups across different grazing intensities

\begin{tabular}{|c|c|c|c|c|c|c|c|c|c|c|}
\hline & Total specie & & Decrease & & Increase & & $\mathbf{P h}$ & synthe & jath & \\
\hline $\begin{array}{l}\text { Plant } \\
\text { functional } \\
\text { group }\end{array}$ & $\begin{array}{l}\text { Number of } \\
\text { species }\end{array}$ & $\%$ & $\begin{array}{l}\text { Number } \\
\text { of species }\end{array}$ & $\%$ & $\begin{array}{l}\text { Number } \\
\text { of } \\
\text { species }\end{array}$ & $\%$ & $\mathrm{C} 3$ & $\mathrm{C} 3 \%$ & $\mathrm{C} 4$ & $\mathrm{C} 4 \%$ \\
\hline PTG & 6 & 7.69 & 3 & 3.85 & - & - & 6 & 7.69 & - & - \\
\hline PSG & 7 & 8.97 & - & - & 3 & 3.85 & 5 & 6.41 & 2 & 2.56 \\
\hline PTF & 18 & 23.08 & 3 & 3.85 & 2 & 2.56 & 14 & 17.95 & 4 & 5.13 \\
\hline PSF & 16 & 20.51 & 2 & 2.56 & 7 & 8.97 & 15 & 19.23 & 1 & 1.28 \\
\hline LILY & 8 & 10.26 & 2 & 2.56 & - & - & 8 & 10.26 & - & - \\
\hline LEGU & 9 & 11.54 & 2 & 2.56 & 2 & 2.56 & 8 & 10.26 & 1 & 1.28 \\
\hline $\mathrm{ABP}$ & 11 & 14.1 & 1 & 1.28 & - & - & 10 & 12.82 & 1 & 1.28 \\
\hline SHR & 3 & 3.85 & - & - & - & - & 3 & 3.85 & - & - \\
\hline Total & 78 & 100 & 13 & 16.66 & 14 & 17.94 & 69 & 88.47 & 9 & 11.53 \\
\hline
\end{tabular}
forbs, $\mathrm{LILY}=$ liliaceae herb, $\mathrm{LEGU}=$ legumes, $\mathrm{ABP}=$ annual/biennial plant, $\mathrm{SHR}=$ shrubs species generally decreased with increasing grazing intensity. Specifically, we identified four palatable species (Leymus chinensis, Bromus inermis, Achnatherum sibiricum, and Vicia amoena) and three of them belong to the PTG functional group. There were six species with medium palatability (Astragalus melilotoides, Lilium tenuifolium, Veronica incana, Galium verum, Clematis hexapetla, and Thalictrum petaloideums) belonging to LEGU, LILY herbs, ABP, and PTF functional groups respectively. 
213 Table 4. Variation of dominant species with high palatability in different plant functional groups across different

214 grazing intensities

\begin{tabular}{llllll}
\hline Functional & Species & NG & LG & MG & HG \\
group & & $\mathbf{0 . 0 0 ~ A U / h}$ & $\mathbf{0 . 2 3} \mathbf{A U} / \mathbf{h}$ & $\mathbf{0 . 4 6} \mathbf{A U} / \mathbf{h}$ & $\mathbf{0 . 9 2} \mathbf{A U / h}$ \\
\hline PTG & Leymus chinensis & $33.6 \pm 7.2 \mathrm{a}$ & $22.2 \pm 2.1 \mathrm{~b}$ & $7.9 \pm 2.5 \mathrm{c}$ & $1.7 \pm 0.86 \mathrm{~d}$ \\
PTG & Bromus inermis & $2.2 \pm 1.2 \mathrm{a}$ & $1.2 \pm 1.3 \mathrm{~b}$ & & $0.04 \pm 0.02 \mathrm{c}$ \\
PTG & Achnatherum & $0.56 \pm 0.4 \mathrm{a}$ & $0.24 \pm 0.1 \mathrm{~b}$ & $0.33 \pm 0.2 \mathrm{~b}$ & $0.17 \pm 0.1 \mathrm{c}$ \\
& sibiricum & & & & \\
LEGU & Astragalus & $0.58 \pm 0.3 \mathrm{a}$ & $0.44 \pm 0.3 \mathrm{a}$ & $0.07 \pm 0.05 \mathrm{~b}$ & $0.01 \pm 0.002 \mathrm{~b}$ \\
& melilotoides & & & & \\
LEGU & Vicia amoena & $0.08 \pm 0.03 \mathrm{a}$ & $0.05 \pm 0.02 \mathrm{a}$ & $0.01 \pm 0.004 \mathrm{~b}$ & $0.01 \pm 0.002 \mathrm{~b}$ \\
LILY & Iris ventricosa & $4.3 \pm 2.2 \mathrm{a}$ & $3.6 \pm 1.2 \mathrm{a}$ & $1.6 \pm 0.57 \mathrm{~b}$ & $0.19 \pm 0.05 \mathrm{c}$ \\
LILY & Lilium tenuifolium & $0.05 \pm 0.03 \mathrm{a}$ & $0.03 \pm 0.003 \mathrm{a}$ & $0.001 \pm 0.001 \mathrm{~b}$ & $0.003 \pm 0.0002 \mathrm{~b}$ \\
ABP & Veronica incana & $0.19 \pm 0.11$ & $0.19 \pm 0.16$ & $0.04 \pm 0.04$ & $0.01 \pm 0.004$ \\
PSF & Heteropappus altaicuc & $2.5 \pm 0.94 \mathrm{a}$ & $1.5 \pm 0.65 \mathrm{~b}$ & $0.3 \pm 0.18 \mathrm{c}$ & $0.002 \pm 0.001 \mathrm{~d}$ \\
PSF & Cymbaria dahurica & $0.7 \pm 0.15 \mathrm{a}$ & $0.5 \pm 0.21 \mathrm{a}$ & $0.5 \pm 0.27 \mathrm{a}$ & $0.1 \pm 0.06 \mathrm{~b}$ \\
PTF & Galium verum & $0.8 \pm 0.14 \mathrm{a}$ & $0.8 \pm 0.29 \mathrm{a}$ & $0.7 \pm 0.28 \mathrm{a}$ & $0.2 \pm 0.06 \mathrm{~b}$ \\
PTF & Clematis hexapetla & $0.2 \pm 0.14 \mathrm{a}$ & $0.07 \pm 0.05 \mathrm{a}$ & $0.12 \pm 0.08 \mathrm{a}$ & $0.001 \pm 0.0001 \mathrm{~b}$ \\
PTF & Thalictrumsquarrosum & $8.9 \pm 3.38 \mathrm{a}$ & $8.4 \pm 2.95 \mathrm{a}$ & $2.6 \pm 0.91 \mathrm{~b}$ & $0.69 \pm 0.22 \mathrm{c}$ \\
\hline
\end{tabular}


226 Table 5. Variation of dominant species with low and medium palatability in different plant functional groups across 227 different grazing intensities

\begin{tabular}{|c|c|c|c|c|c|}
\hline $\begin{array}{l}\text { Functional } \\
\text { group }\end{array}$ & Species & $\begin{array}{l}\text { NG } \\
0.00 \mathrm{AU} / \mathrm{h}\end{array}$ & $\begin{array}{l}\text { LG } \\
0.23 \mathrm{AU} / \mathrm{h}\end{array}$ & $\begin{array}{l}\text { MG } \\
0.46 \mathrm{AU} / \mathrm{h}\end{array}$ & $\begin{array}{l}\text { HG } \\
0.92 \mathrm{AU} / \mathrm{h}\end{array}$ \\
\hline PSG & Carex duriuscula & $12.4 \pm 3.5 \mathrm{~d}$ & $20.8 \pm 3.1 \mathrm{c}$ & $29.6 \pm 4.05 b$ & $42.8 \pm 3.5 \mathrm{a}$ \\
\hline PSG & Cleistogenes squarrosa & $1.3 \pm 0.66 \mathrm{c}$ & $3.5 \pm 0.76 b$ & $4.4 \pm 1.1 b$ & $6.2 \pm 1.7 \mathrm{a}$ \\
\hline PSG & Koeleria cristata & $0.61 \pm 0.52 b$ & $0.63 \pm 0.20 \mathrm{~b}$ & $1.8 \pm 0.70 \mathrm{a}$ & $2.02 \pm 0.61 \mathrm{a}$ \\
\hline LEGU & Astragalus adsurgens & $0.04 \pm 0.033 c$ & $0.33 \pm 0.15 b$ & $0.58 \pm 0.17 \mathrm{a}$ & $0.98 \pm 0.25 \mathrm{a}$ \\
\hline LEGU & Oxytropis myriophylla & $0.04 \pm 0.04 \mathrm{c}$ & $0.02 \pm 0.001 \mathrm{c}$ & $0.13 \pm 0.09 b$ & $1.0 \pm 0.44 \mathrm{a}$ \\
\hline PSF & Pulsatilla turczaninovii & $4.3 \pm 0.97 b$ & $4.3 \pm 0.81 \mathrm{~b}$ & $7.6 \pm 1.2 \mathrm{a}$ & $7.1 \pm 1.3 \mathrm{a}$ \\
\hline PSF & Potentilla acaulis & $0.07 \pm 0.04 \mathrm{c}$ & $0.73 \pm 0.41 b$ & $1.00 \pm 0.6 \mathrm{~b}$ & $3.03 \pm 1.1 \mathrm{a}$ \\
\hline PSF & Potentilla verticillaris & $0.11 \pm 0.01 \mathrm{~b}$ & $0.16 \pm 0.07 \mathrm{~b}$ & $0.33 \pm 0.16 \mathrm{~b}$ & $0.71 \pm 0.13 \mathrm{a}$ \\
\hline PSF & Taraxacum mongolicum & $0.001 \pm 0.0001 \mathrm{c}$ & $0.09 \pm 0.010 \mathrm{~b}$ & $0.09 \pm 0.05 b$ & $1.4 \pm 0.5 \mathrm{a}$ \\
\hline PSF & Potentilla tanacetifolia & $0.03 \pm 0.02 b$ & $0.09 \pm 0.03 b$ & $0.30 \pm 0.20 \mathrm{a}$ & $0.70 \pm 0.32 \mathrm{a}$ \\
\hline PSF & Sibbaldia adpressa & & $0.04 \pm 0.02 b$ & $0.09 \pm 0.07 \mathrm{~b}$ & $1.02 \pm 0.23 \mathrm{a}$ \\
\hline PTF & Artemisia tanacetifolia & $9.1 \pm 1.47 \mathrm{a}$ & $10.9 \pm 2.48 \mathrm{a}$ & $11.7 \pm 2.90 \mathrm{a}$ & $11.3 \pm 2.17 \mathrm{a}$ \\
\hline PTF & Schizonepeta multifida & $0.17 \pm 0.12 \mathrm{~b}$ & $0.22 \pm 0.07 \mathrm{~b}$ & $1.3 \pm 0.5 \mathrm{a}$ & $0.97 \pm 0.43 \mathrm{a}$ \\
\hline
\end{tabular}


Gamma species diversity and its composition (Alpha and Beta) were consistently higher in PTG,
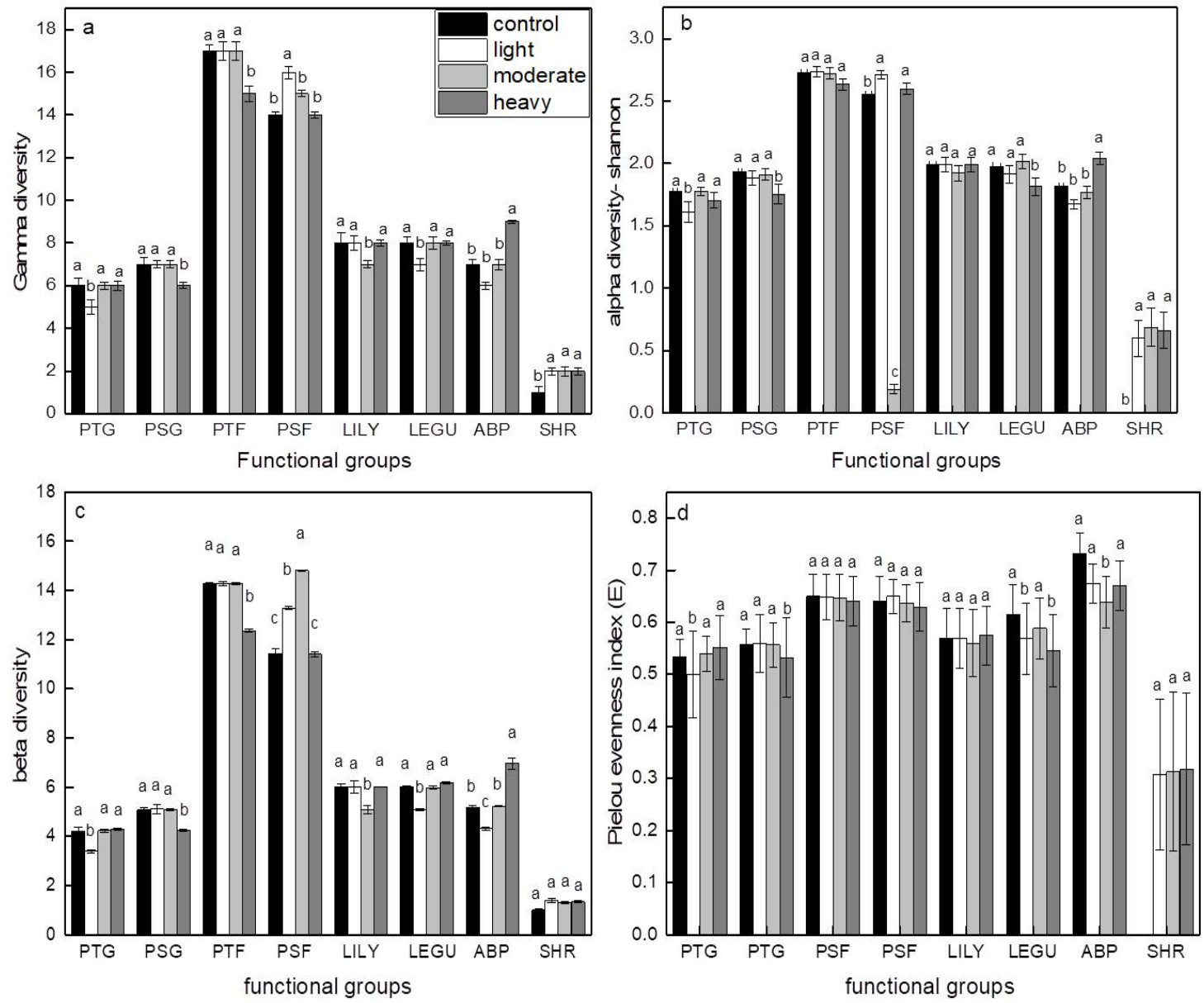

LEGU, ABP, SHR, and lower in PSG and PSF (Fig. 2). The contribution of $\beta$ diversity to gamma diversity in Hulunbuir grassland is slightly greater than that of $\alpha$ diversity (Fig. $2 b$ and c). The contribution of $\alpha$ and $\beta$ diversity of the eight PFGs across the grazing intensities to $\gamma$ diversity was different (Fig. 2a-2c). Species diversity was higher in PTF and PSF than other functional groups. The high diversity in PTF and PSF was mainly due to the higher number of species richness in these functional groups. We also found a significant difference $(p<0.05)$ in Pielou evenness of the eight PFGs across the grazing intensities (Fig. 2d). The evenness index was generally higher for PSF and LILY herbs across the grazing intensities, while PTG and LEGU recorded the lowest values in the HG treatment.

Fig. 2. Comparisons of (a) Gamma diversity ( $\gamma$ ), (b) Alpha diversity ( $\alpha$ ), (c) Beta diversity ( $\beta$ ), and (d) Pielou Evenness of eight plant functional groups across different grazing intensities in Hulunbur grassland, Inner Mongolia. PTG: Perennial tall grass, PSG: Perennial short grass, PTF: Perennial tall forbs, PSF: Perennial short forbs, LILY: Liliaceae herb, LEGU: Legume, ABP: Annual/biennial plant, SHR: Shrub. Error bars indicate the standard error $(( \pm \mathrm{SE})$ of the mean $(\mathrm{p} \leq 0.05)$. 


\section{Discussion}

Livestock grazing may modify plant community structure, thereby leading to changes in vegetation characteristics. Across the length of the grazing season, several species could grow and become established within the grazing environment. Our findings demonstrate that species richness was consistently higher under LG and MG compared with the NG and HG intensities. This may be related to grazing history and the rate of species disappearance during defoliation in the HG plot (Marty 2005; Noy-Meir, et al. 1989). The trampling and nibbling effect of cattle led to reduced biomass through the removal of tall species and consequently result in changes in competitive interactions, which enabled less aggressive species to grow and hence a higher species richness in the community (Sternberg, et al. 2000). Several studies have proposed that grazing intensity and biodiversity converge in a general 'dominance disturbance theory' (Grime 1979; Sternberg, et al. 2000). Our results on the relationship between grazing intensity and species richness support this theory. In sum, species richness increased in both LG and MG plots.

We found that the effect of LG and MG on species richness did not differ and this may be related to

262 the presence of grazing tolerant species in the treatments. Species richness was observed to be lower under 263 HG intensity. There was no visible effect of light grazing during the plant growth period. Transition in 264 PFGs as a result of grazing intensity has been documented in the literature (Papanikolaou, et al. 2011; 265 Wang, et al. 2019; Wu, et al. 2014b). Our analysis of functional groups showed a decline in the PTF in the 266 HG plot only. Similarly, PSGs declined in the NG and HG plots. These results contradicted the earlier report by (Papanikolaou, et al. 2011) who reported that the richness of both perennial grasses and forbs increased with grazing intensity. The difference between the former and present study may be related to vegetation type (Wu, et al. 2014b). However, our result is similar to the findings by (Fernández Alés, et al. 1993). In contrast, shrubs and legumes functional groups were less affected by grazing intensity. Their persistence is related to the development of chemical and/or physical defense substances such as chemical secretions and capillaries, as well as the possession of spiny leaves. They are also less dependent on seed production than other species. This strategy allows for rapid growth and early establishment after the first rainfall and improves grazing tolerance.

Our results showed that the total aboveground biomass of the PFGs decreased with increasing grazing intensity, and this is consistent with earlier reports (Wang, et al. 2016; Wu, et al. 2014a). Moreover, the plant composition changed due to the differential response of the PFGs to grazing intensity, which is weaker 
community composition is broadly driven by the decline in the biomass of the palatable species (especially PTG functional groups) and the increase in the aboveground biomass of ABP plants. These results agree with the previous study by (Sternberg, et al. 2015) that an increase in grazing intensity increases the dominant species of Gramineae which comprises of the most palatable species of grasses and forbs.

283 Notably, some functional groups increased (e.g., ABP and SHR) while others decreased (e.g., PTG, PTF, 284 and LILY) as grazing intensifies. This may be attributed to the higher probability of the tall grasses being 285 defoliated by the grazing animals, thereby increasing light interception by the understory plants (Pekin, et al. 2014). Also, the reduction of some functional groups could have increased the competitive ability of others. In grassland ecosystems, however, dominant species have been reported to exhibit significant resistance or tolerance to grazing through a series of adaptive mechanisms (e.g., secretion of chemical defense substances) when the grazing condition changes (Aboling, et al. 2008; Ruppert, et al. 2015).

Species with different photosynthetic pathways have a different physiological and ecological response to grazing (Wang 2002). Animals accidentally eat some plants while they graze. Animals eager for fresh grass may accidentally bite off the crown of toxic species when they have nothing else to eat. This may explain the decrease of LILY functional group with grazing intensities

Grassland management decisions must, therefore, take seasonal development patterns and grassland succession into account, both of which are closely related to photosynthetic pathways. In Hulunbuir grassland, grazing induces the abundance of $\mathrm{C} 4$ species at the early succession stage. This is because the capacity.

In this study, we found only nine species with the $\mathrm{C} 4$ photosynthetic pathway, while the majority of others (67 in total) have $\mathrm{C} 3$ pathways. The relatively low quantity of $\mathrm{C} 4$ species could be premised on the relative abundance of species within the eight PFGs. Our results suggested that $\mathrm{C} 4$ species are common in forbs than other PFGs and this corroborates the earlier report by (Wang 2002) that grazing intensity significantly influenced the abundance of C3 plants in a 4-year trial. Whereas C3 plants decreased with increasing grazing intensity, we found that the C4 plant increased as grazing intensifies. Simultaneously, summer temperatures also increased, providing an alternative explanation for the observed increase in $\mathrm{C} 4$ plants.

In Hulunbuir grassland, the structure and composition of the species change over time and space. Our 308 results indicated that the species composition and abundance of all the eight PFGs are dynamic, thus, the 309 different PFGs provide fodders of different quality at the same time of grazing season. (Tserendash and 310 Erdenebaatar 1993) describes the early summer flowering contents of the species Koeleria cristata, Poa 311 partenis, and Agropyron cristatum in steppe ecosystems. Notably, at the same time of the year, Carex spp 
showed late flowering. More importantly, in the growing season, the feeding C4 plants showed compensatory growth after grazing.

The patterns of species grown under different water ecotype can help us to understand the community structure, diversity and productivity of temperate grassland (Fay, et al. 2002; Fowler 1986; Köchy and Wilson 2000; Tsialtas, et al. 2001; Weltzin and McPherson 1997). The dominant species, Leymus chinensis, Bromus inermis, Achnatherum sibiricum and Vicia amoena were relatively higher in grasses and legumes. In total, 78 plant species belonging to eight functional groups $(16.66 \%)$ decreased, while $17.94 \%$ increased with grazing intensity. Livestock grazing plays a significant role in plant species diversity and vegetation composition of grasslands (Cingolani, et al. 2003; Pucheta, et al. 2004). Light and moderate grazing intensity recorded higher plant species diversity compared with the NG and HG intensity. This implies that HG intensity resulted in a decrease in the species diversity of Hulunbuir grassland (Kikoti and Mligo 2015). Further, our results showed a decrease and increase in the palatable (e.g., Bromus inermis) and less palatable (e.g., Pulsatilla turczaninovii) species as grazing intensified. This finding concurs with the report by (Ji, et al. 2020) who reported an increase in the unpalatable aboveground biomass in total aboveground biomass with increasing grazing intensity. Also, the observed trend can be attributed to the selective defoliation of palatable species by the grazing animals (Liu, et al. 2015; Venter, et al. 2019) which leads to a decline in competition for resources (Ma, et al. 2019) and this was more evident in the HG plot.

The intensity of grazing is a key determinant of the spatio-temporal pattern of grassland resource utilization by livestock. The impact of grazing on plant species diversity can also be explained relative to individual species' responses because of the variation in plants resistance and tolerance to grazing. Specifically, Leymus chinensis and Achnatherum sibiricum which were palatable species accounted for the highest important value of biomass in the NG plot. With increasing grazing density, Leymus chinensis gradually decreased due to preferential selection by the grazing animals (Liu, et al. 2016), hence, it represents the lowest value of aboveground biomass among the dominant species in the HG treatment. As grazing intensifies, Carex duriuscula and pulsatilla turczaninovii gradually become the dominant species in the HG plot. Overall, it can be inferred that the response of the aboveground biomass of both the palatable and less palatable species differ across the grazing intensities adopted in this study.

Plant species with different growth and reproductive phenology may have different responses to 340 grazing intensities across the length of the grazing season. In this study, the response of individual species 341 to different grazing intensities is different; however, the same number of positive and negative reactions 342 among different species did not affect plant species richness and diversity. In general, the response of 343 vegetation to grazing intensity may be strongly dependent on or overridden by vegetation type ( $\mathrm{Wu}$, et al. 344 2014a). Therefore, grazing intensity is the most important grazing management variable affecting the plant 345 community structure in grassland ecosystems (Hickman, et al. 2004). 
The contribution of $\alpha$ and $\beta$ diversity to $\gamma$ diversity is the basis of understanding the composition of biodiversity (Jost 2007; Zhang, et al. 2014). There are different opinions on the relative importance of $\alpha$ and $\beta$ diversity as a function of $\gamma$ diversity. Whereas some researchers hold the view that $\alpha$ diversity is more important, others attached a higher value to $\beta$ diversity while some groups of scholars believe that the two

350 (i.e., $\alpha$ and $\beta$ ) are of equal importance (Jost 2007; Meynard, et al. 2011). In this study, we found that $\beta$

351 diversity contributes to gamma diversity more than $\alpha$ diversity for all PFGs across the grazing intensity and 352 that total diversity is greater in species-rich PFGs (e.g., PTG and PSF) than species-poor PFGs (e.g., SHR 353 and PTF). The relative contribution of $\alpha$ and $\beta$ to $\gamma$ diversity of the grassland community depends on the 354 extent of species diffusion and ecological heterogeneity (Chiarucci, et al. 2010; Crist and Veech 2006).

355 Alpha diversity is more important in the community with a homogeneous environment and species with 356 high diffusion potential, while $\beta$ diversity is more important in the community with a heterogeneous environment and species with weak diffusion potential. The observed increased in diversity of the functional groups may be attributed to species richness and this strengthens the high diversity recorded in species-rich functional groups. The results of the functional group diversity recorded across the grazing intensities were consistent with those reported earlier (Carlson 2011; Harrison, et al. 2003; Schultz, et al. 2011).The differences in the evenness of the PFGs in the various grazing intensity treatments depends on the difference between the PFGs (Stirling and Wilsey 2001). Because species evenness index and richness might respond differently to different grazing intensity and environmental variables, we found different responses of plant functional groups to evenness. The grazing density had differential impact on diversity, even though 78 plant species were included in every season.

\section{Conclusions}

367 In this study, various sensitive indices of long-term grazing were set and evaluated. Grazing intensity had a different effect on (change vegetation composition) depends on the productivity and plant functional groups of grassland communities. There was a significant negative effect of grazing intensity on the aboveground biomass (AGB). Therefore, the grazing intensity levels are inverted the grazing pressure from

371 non-grazing to heavy grazing intensity. AGB can be used as a potential sensitive index for meadow 372 productivity. In this study, LG and HG represent the best and worst responses of aboveground biomass to 373 grazing, respectively. We found that the richness of the PFGs only differed for PSG and LILY across the grazing intensities. Perennial short grass species were higher in the LG and MG plots. The PTG showed

375 significantly decreased with grazing intensity, while PSG increased with grazing intensity. Also, this study 376 showed that the effect of grazing density on grassland diversity was consistently higher in tall herbaceous 377 (PTG, LEGU, ABP, SHR) and lower in short herbaceous (PSG and PSF). 
The results of this study considerably contribute to the sustainable management of grassland resources in the study area. In addition, the results provide a perspective for evaluating current grazing management scenarios and carrying out timely adaptive practices, so as to maintain the ability of the grassland system to perform its ecological functions in the long term.

\section{Funding}

385 This research was supported by the national key research and development program (2016YFC0500608, 2016YFC0500601), the Natural Science Foundation (31971769), the basic research fund of central nonprofit scientific institutions (161013209031, Y2019YJ13, Y2020YJ19), and the special fund of modern agricultural technology system of the Chinese ministry of agriculture (CARS-34) and Hulunbuir Science and Technology Project (YYYFHZ201903).

390

391

392

\section{Acknowledgments}

We thank the staff of Hulunbuir Grassland Ecosystem Research Station for their assistance during field sampling, and our colleagues from the Agricultural Resources and Regional Planning Institute for helping us to make these figures.

\section{Author Contributions}

Conceptualization, Y.M.Z and X.X; Main analysis, Y.M.Z, A.I.A and C.J; Visualization, Y.M.Z and R.Y.; Writing original draft, Y.M.Z and J.S.O; Supervision, X.X and R.Y; Funding and project administration, X.X; Writing: draft editing and Review, X.X and R.Y; Y.M.Z, R.Y, and A.I.A authors have been equally contributed in this paper; all authors have read and agreed to the published version of the manuscript.

\section{Conflicts Of Interest}

The authors declare no conflict of interest.

\section{References}

Aboling, S., et al.2008.Effects of cattle grazing timing and intensity on soil seed banks and regeneration strategies in a Mediterranean grassland. Community Ecology 9(1):97-106. Bakker, Jan P.1998.The impact of grazing on plant communities. In Grazing and conservation 
management. Pp. 137-184: Springer.

Bergmeier, Erwin, Freiburg Dimopoulos, and Panayotis Dimopoulos.2003 .The vegetation of islets in the Aegean and the relation between the occurrence of islet specialists, island size, and grazing. Phytocoenologia 33(2-3):447-474.

Carlson, Amanda 2011.Effects of grazing on native plant abundance and diversity in a California grassland invaded by Phalaris aquatica. Grazing and Native vegetation:1-21.Chiarucci, Alessandro, et al.2010 Additive partitioning as a tool for investigating the flora diversity in 91. oceanic archipelagos. Perspectives in Plant Ecology, Evolution and Systematics 12(2):83-

Cingolani, Ana M., et al.2003. Combined effects of environment and grazing on vegetation structure in Argentine granite grasslands. Journal of Vegetation Science 14(2):223-232.

Crist, T. O., and J. A. Veech, 2006.Additive partitioning of rarefaction curves and species-area relationships: unifying alpha-, beta- and gamma-diversity with sample size and habitat area. Ecol Lett 9(8):923-32.

De Bello, Francesco, Jan Lepš, and Maria-Teresa Sebastià 2006.Variations in species and functional plant diversity along climatic and grazing gradients. Ecography 29(6):801-810.

DÍAz, Sandra, et al. 2007.Plant trait responses to grazing ? a global synthesis. Global Change Biology 13(2):313-341.

Díaz, Sandra, Imanuel Noy-Meir, and Marcelo Cabido 2001.Can grazing response of herbaceous 508. plants be predicted from simple vegetative traits? Journal of Applied Ecology 38(3):497-

Dumont, Bertrand, et al. 2009. How does grazing intensity influence the diversity of plants and insects in a species-rich upland grassland on basalt soils? Grass and Forage Science 64(1):92-105.

Facelli, JosÉ M., and Heather Springbett 2009. Why do some species in arid lands increase under grazing? Mechanisms that favour increased abundance ofMaireana pyramidatain overgrazed chenopod shrublands of South Australia. Austral Ecology 34(5):588-597.

Fanselow, Nicole, et al. 2011. Short-term regrowth responses of four steppe grassland species to grazing intensity, water and nitrogen in Inner Mongolia. Plant and Soil 340(1-2):279289.

Fay, Philip A., et al. 2002. Altered rainfall patterns, gas exchange, and growth in grasses and 
forbs. International Journal of Plant Sciences 163(4):549-557.

Fernández Alés, R., J. M. Laffarga, and F. Ortega 1993. Strategies in Mediterranean grassland annuals in relation to stress and disturbance. Journal of Vegetation Science 4(3):313-322.

Foggin, J. Marc 2008. Depopulating the Tibetan grasslands. Mountain Research and Development 28(1):26-31.

Fowler, Norma L. 1986.Microsite requirements for germination and establishment of three grass species. American Midland Naturalist:131-145.

Grime, John Philip 1979.Plant strategies and vegetation processes. Plant strategies and vegetation processes.

Harrison, S., B. D. Inouye, and H. D. Safford 2003. Ecological heterogeneity in the effects of grazing and fire on grassland diversity. Conservation Biology 17(3):837-845.

Hickman, Karen R., et al. 2004. Grazing management effects on plant species diversity in tallgrass prairie. Rangeland Ecology and Management 57(1):58-65.

Heady, Harold F. 1964.Palatability of herbage and animal preference. Rangeland Ecology \& Management/Journal of Range Management Archives 17(2):76-82.

Hill, Mark O.1973.Diversity and evenness: a unifying notation and its consequences. Ecology 54(2):427-432.

Ji, Lei, et al. 2020. Impacts of livestock grazing on vegetation characteristics and soil chemical properties of alpine meadows in the eastern Qinghai-Tibetan Plateau. Ecoscience 27(2):107-118.

464 Köchy, Martin, and Scott D. Wilson 2000.Competitive effects of shrubs and grasses in prairie.

$$
\text { Oikos 91(2):385-395. }
$$


Le, C., et al. 2014. Grassland degradation caused by tourism activities in Hulunbuir, Inner Mongolia, China, 2014. Vol. 18, pp. 012137. IOP Publishing.

Liu, Chen, et al. 2016.Effects of grazing on soil nitrogen spatial heterogeneity depend on

Liu, Jun, et al. 2015.Impacts of grazing by different large herbivores in grassland depend on plant species diversity. Journal of Applied Ecology 52(4):1053-1062.

Ma, Qingqing, et al. 2019. Quantifying grazing intensity using remote sensing in Alpine Meadows on Qinghai-Tibetan plateau. Sustainability 11(2):417.

Ma, W., et al. 2010. Changes in individual plant traits and biomass allocation in alpine meadow

Marty, Jaymee T. 2005. Effects of Cattle Grazing on Diversity in Ephemeral Wetlands. Conservation Biology 19(5):1626-1632.

McIntyre, S., et al. 1999. Disturbance response in vegetation-towards a global perspective on functional traits. Journal of vegetation Science 10(5):621-630.

Meynard, Christine N., et al. 2011.Beyond taxonomic diversity patterns: how do $\alpha, \beta$ and $\gamma$ components of bird functional and phylogenetic diversity respond to environmental gradients across France? Global Ecology and Biogeography 20(6):893-903.

Montalvo, J., et al. 1993. Species diversity patterns in Mediterranean grasslands. Journal of Vegetation Science 4(2):213-222.

Noy-Meir, I., M. Gutman, and Y. Kaplan 1989. Responses of Mediterranean grassland plants to grazing and protection. The journal of Ecology:290-310.

Olff, Han, and Mark E. Ritchie 1998 Effects of herbivores on grassland plant diversity. Trends in

491 Papanikolaou, Alexandra D., et al. 2011. Grazing effects on plant functional group diversity in Mediterranean shrublands. Biodiversity and Conservation 20(12):2831-2843.

493 Pekin, Burak K., et al. 2014. Ungulate browsing maintains shrub diversity in the absence of 
episodic disturbance in seasonally-arid conifer forest. PloS one 9(1):e86288.

Proulx, Marc, and Asit Mazumder 1998. Reversal of grazing impact on plant species richness in nutrient-poor vs. nutrient-rich ecosystems. Ecology 79(8):2581-2592.

Pucheta, Eduardo, et al. 2004.Below-ground biomass and productivity of a grazed site and a neighbouring ungrazed exclosure in a grassland in central Argentina. Austral Ecology 29(2):201-208.

Ruppert, J. C., et al. 2015. Quantifying drylands' drought resistance and recovery: the importance of drought intensity, dominant life history and grazing regime. Glob Chang Biol 21(3):1258-70.

Saccone, Patrick, et al. 2014.Environmental perturbation, grazing pressure and soil wetness jointly drive mountain tundra toward divergent alternative states. Journal of Ecology 102(6):1661-1672.

Schultz, Nick L., John W. Morgan, and Ian D. Lunt 2011. Effects of grazing exclusion on plant species richness and phytomass accumulation vary across a regional productivity gradient. Journal of Vegetation Science 22(1):130-142.

Sepkoski Jr, J. John 1988. Alpha, beta, or gamma: where does all the diversity Paleobiology:221234.

Sternberg, M., et al.2015.Testing the limits of resistance: a 19-year study of Mediterranean grassland response to grazing regimes. Glob Chang Biol 21(5):1939-50.

Sternberg, Marcelo, et al.2000.Vegetation response to grazing management in a Mediterranean herbaceous community: a functional group approach. Journal of Applied Ecology 37(2):224-237.

Stirling, Gray, and Brian Wilsey 2001.Empirical relationships between species richness, evenness, and proportional diversity. The American Naturalist 158(3):286-299.

Suding, Katharine N., et al. 2008. Scaling environmental change through the community-level: a trait-based response-and-effect framework for plants. Global Change Biology 14(5):1125-1140.

Thomas, Haydn J. D., et al. 2019. Traditional plant functional groups explain variation in economic but not size-related traits across the tundra biome. Global ecology and biogeography 28(2):78-95.

Tserendash, S., and B. Erdenebaatar 1993.Performance and management of natural pasture in 
Mongolia. Nomadic Peoples:9-15.

526

527

528

529

530

531

532

533

534

535

536

537

538

539

540

541

542

543

544 545

546

547

548

549

550

551

552

553

554
Tsialtas, J. T., et al.2001. Interspecific variation in potential water-use efficiency and its relation to plant species abundance in a water-limited grassland. Functional Ecology 15(5):605614.

Venter, Zander S., Heidi-Jayne Hawkins, and Michael D. Cramer 2019.Cattle don’t care: Animal behaviour is similar regardless of grazing management in grasslands. Agriculture, Ecosystems \& Environment 272:175-187.

Verdú, José R., et al.2007.Grazing promotes dung beetle diversity in the xeric landscape of a Mexican Biosphere Reserve. Biological Conservation 140(3-4):308-317.

Wang, Jianxun, et al.2016.Response of plant functional traits to grazing for three dominant species in alpine steppe habitat of the Qinghai-Tibet Plateau, China. Ecological Research 31(4):515-524.

Wang, R. Z. 2002. Photosynthetic pathway types of forage species along grazing gradient from the Songnen grassland, Northeastern China. Photosynthetica 40(1):57-61.

Wang, Suizi, et al. 2019. Effects of grazing exclusion on biomass growth and species diversity among various grassland types of the Tibetan Plateau. Sustainability 11(6):1705.

Weltzin, Jake F., and Guy R. McPherson 1997. Spatial and temporal soil moisture resource partitioning by trees and grasses in a temperate savanna, Arizona, USA. Oecologia 112(2):156-164.

Whittaker, Robert H.1972. Evolution and measurement of species diversity. Taxon 21(2-3):213251.

Whittaker, Robert H., and Whittaker Rh 1977. Evolution of species diversity in lan communities.

Wilson, Laurel R., et al. 2016.Plant community response to regional sources of dominant grasses in grasslands restored across a longitudinal gradient. Ecosphere 7(4):e01329.

Wu, Gao-Lin, et al. 2014a. Above- and Belowground Response along Degradation Gradient in an Alpine Grassland of the Qinghai-Tibetan Plateau. CLEAN - Soil, Air, Water 42(3):319-323.

$\mathrm{Wu}$, Jianshuang, et al. 2014b. Effects of grazing exclusion on plant functional group diversity of alpine grasslands along a precipitation gradient on the northern Tibetan Plateau. Arctic, antarctic, and alpine research 46(2):419-429. 
bioRxiv preprint doi: https://doi.org/10.1101/2021.05.24.445414; this version posted May 24, 2021. The copyright holder for this preprint (which

was not certified by peer review) is the author/funder, who has granted bioRxiv a license to display the preprint in perpetuity. It is made available under aCC-BY 4.0 International license.

555 Yan, Y., and X. Lu 2015. Is grazing exclusion effective in restoring vegetation in degraded

556 alpine grasslands in Tibet, China? PeerJ 3:e1020.

557 Zhang, Q., et al. 2014. Alpha, beta and gamma diversity differ in response to precipitation in the 558 Inner Mongolia grassland. PLoS One 9(3):e93518.

559 